\title{
PENGARUH KEPRIBADIAN (PERSONALITY) DAN KEINGINAN UNTUK BERTINDAK (INTENTION TO ACT) TERHADAP PERILAKU TANGGUNG JAWAB LINGKUNGAN (RESPONSIBLE ENVIRONMENTAL BEHAVIOR) SISWA
}

\author{
Tiara Agustiani Mahardika ${ }^{1}$, I Made Putrawan ${ }^{2}$, Diana Vivanti Sigit ${ }^{3}$ \\ ${ }^{1}$ Student of Biology Education Department of State University of Jakarta \\ ${ }^{2}$ Environmental Education Department of State University of Jakarta \\ ${ }^{3}$ Biology Education Department of State University of Jakarta \\ Email: tiaraagustiani17@gmail.com
}

\begin{abstract}
Environmental damage is intentionally done by individuals or groups of people. Understanding of environmental education involves various parties including one of them students. Behavior of responsibility possessed by students is supported by the personality and desire to act in dealing with environmental problems. This study was aimed at finding effect personality and intention to act toward responsible environmental behavior students. Research conducted at SMAN 31 Jakarta on the Semester I of 2019/2020 school year. The method used is a survey method through causal studies and analyzed by path analysis. The research instruments used were responsible environmental behavior ( 27 items, reliability 0.763 ), personality ( 26 items, reliability 0.820 ), and intention to act (30 items, reliability 0.904$)$. The results showed that personality has a direct effect on the intention to act, intention to act has a direct effect on responsible environmental behavior, personality has a direct effect on responsible environmental behavior, and the results of intention to act are suitable as mediating variables between personality and responsible environmental behavior on students.
\end{abstract}

Keywords: Student, Personality, Intention to Act, Responsible Environmental Behavior, Reliability. 


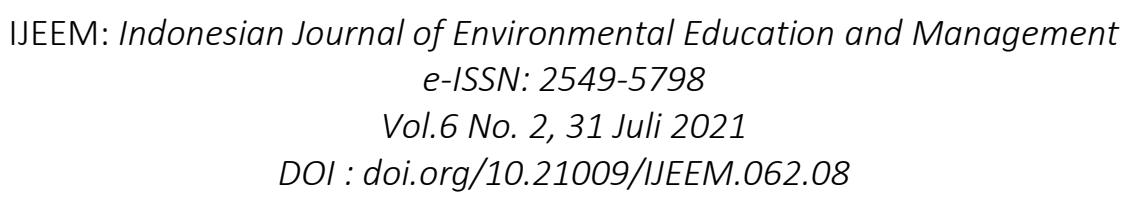

\section{PENDAHULUAN}

Perusakan lingkungan hidup adalah tindakan yang menimbulkan perubahan langsung atau tidak langsung terhadap sifat fisik dan atau hayatinya yang mengakibatkan lingkungan hidup tidak berfungsi lagi dalam menunjang pembangunan berkelanjutan. Tindakan perusakan lingkungan ini dilakukan sengaja oleh sekelompok atau seorang individu secara sadar. Masalah perusakan lingkungan akan terus terjadi apabila tidak adanya kesadaran dari masing-masing individu. Hal ini harus diperbaiki dari pendidikan lingkungan yang membangun berpikir kritis siswa dalam menghadapi permasalahan lingkungan hidup.

Pendidikan lingkungan adalah hal yang harus ditanami sejak dini. Dalam menanamkan pendidikan lingkungan bagi setiap siswa diperlukan kerja sama dari berbagai pihak, baik guru maupun siswa. Dengan berjalanya waktu akan muncul sikap perilaku tanggung jawab lingkungan (Responsible Environmental Behavior) yang dimiliki oleh siswa. Perilaku tanggung jawab siswa di dukung oleh adanya kepribadian dan keinginan untuk bertindak dalam model Hines sebagai berikut:

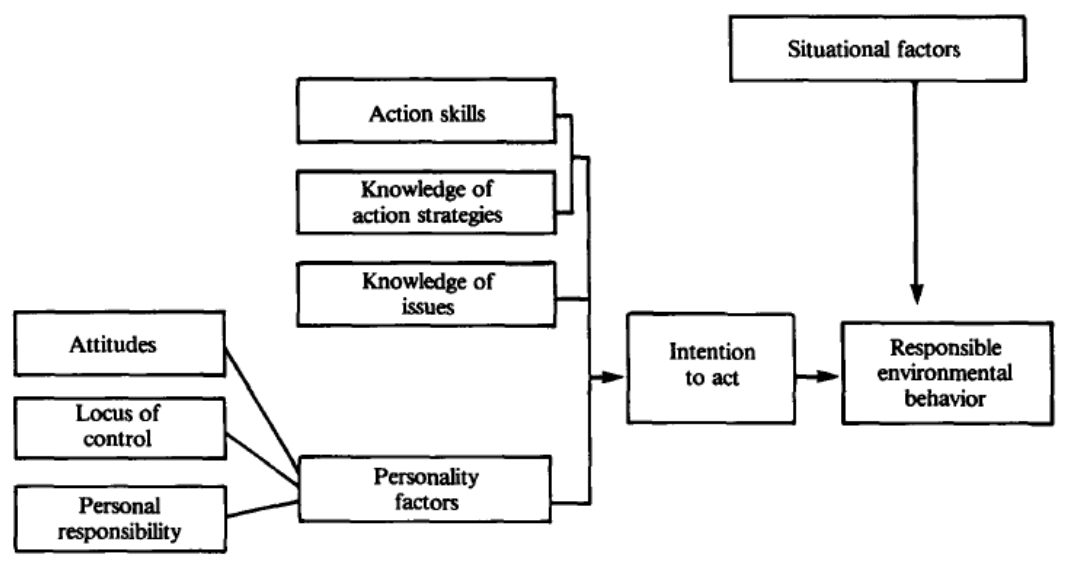

Gambar 1. Model Hines

Menurut Colquitt, terdapat 5 dimensi yang perlu diperhatikan dalam personality yaitu: (1) openness (terbuka terhadap pengalaman); (2) conscientiousness (kesungguhan); (3) extraversion (ekstraversi); (4) agreeableness (keramahan); dan (5) neuroticism (stabilitas emosi). Kepribadian inilah yang nanti akan memunculkan keinginan untuk bertindak dan perilaku tanggung jawab bagi siswa. 


\section{IJEEM: Indonesian Journal of Environmental Education and Management e-ISSN: 2549-5798 \\ Vol.6 No. 2, 31 Juli 2021 \\ DOI : doi.org/10.21009/IJEEM.062.08}

Menurut Fishbein dan Ajzen yaitu keinginan untuk bertindak, mengacu pada kemungkinan subjektif seseorang bahwa dia akan melakukan beberapa tindakan. Intensi atau keinginan didefinisikan sebagai penilaian tentang perilakunya. Keinginan diperkenalkan sebagai komponen mediator antara sikap dan perilakunya, yaitu sikap melayani untuk mengarahkan keinginan yang lebih baik.

Faktor sentral dalam teori perilaku terencana adalah niat individu untuk melakukan suatu pemberian tingkah laku atau intension. Niatnya dianggap menangkap faktor motivasi itu mempengaruhi suatu perilaku; mereka adalah indikasi betapa sulitnya orang mau untuk mencoba, berapa banyak upaya yang mereka rencanakan untuk lakukan, agar lakukan perilakunya. Sebagai aturan umum, semakin kuat niat untuk terlibat dalam suatu perilaku, semakin besar kemungkinan kinerjanya. Dengan niat yang terencana ini akan membuat perilaku tanggung jawab lingkungan. Menurut Van Liere dan Dunlap memandang responsible environmental behavior sebagai ekspresi atau dimensi kepedulian lingkungan yang terdiri dari kegiatan yang mengusulkan bagaimana individu memecahkan masalah lingkungan. Responsible environmental behavior dijelaskan sebagai hubungan di mana peningkatan pengetahuan sikap yang menguntungkan pada gilirannya menyebabkan tindakan yang menguntungkan terhadap lingkungan.

Berdasarkan uraian diatas maka rumusan masalah dalam penelitian ini adalah : (1) apakah personality berpengaruh langsung terhadap intention to act siswa ? ; (2) apakah intention to act berpengaruh langsung terhadap responsible environmental behavior ? ; (3) apakah personality berpengaruh langsung terhadap responsible environmental behavior ?;(4) apakah personality berpengaruh tidak langsung terhadap responsible environmental behavior melalui intention to act siswa ?. Penelitian ini bertujuan untuk mengetahui pengaruh personality dan intention to act terhadap responsible environmental behavior siswa.

\section{METODOLOGI PENELITIAN}

Metode penelitian yang digunakan adalah metode survei yang bersifat kausal. Penelitian ini menggunakan analisis jalur ( path analysis) yang dipilih untuk menganalisis pola hubungan antar variabel dengan tujuan untuk mengetahui pengaruh secaa langsung maupun tidak langsung antara variabel eksogen dan endogen. Penelitian ini mempunyai 3 


\section{IJEEM: Indonesian Journal of Environmental Education and Management \\ e-ISSN: 2549-5798 \\ Vol.6 No. 2, 31 Juli 2021 \\ DOI : doi.org/10.21009/IJEEM.062.08}

variabel, variabel eksogen $\left(\mathrm{X}_{1}\right)$ adalah personality dan variabel eksogen $\left(\mathrm{X}_{2}\right)$ adalah intention to act. Sedangkan variabel endogen $\left(\mathrm{X}_{3}\right)$ adalah responsible environmental behavior. Penelitian ini dilakukan di SMAN 31 di Jakarta dengan total jumlah sampel 97 siswa. Instrumen penelitian Instrumen penelitian yang digunakan adalah perilaku tanggung jawab (27 butir, reliabilitas 0.763), kepribadian (26 butir, reliabilitas 0.820), dan keinginan untuk bertindak (30 butir, 0.904). Model penelitian digambarkan sebagai berikut :

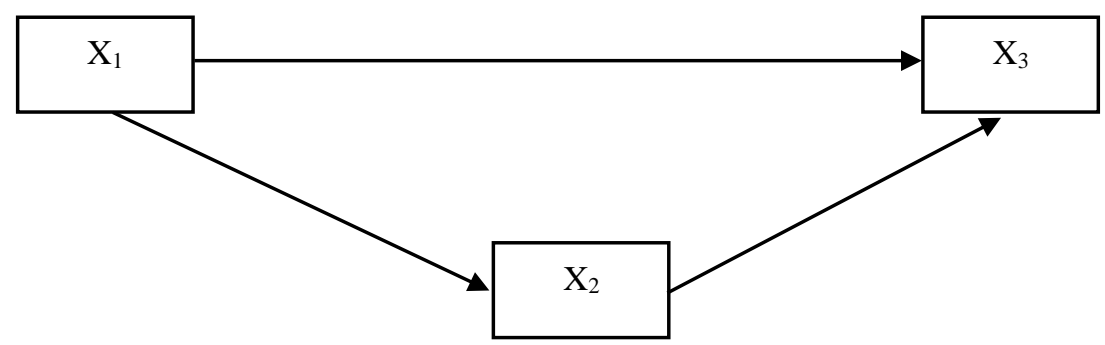

Gambar 2. Model Hipotetik

Keterangan :

$\mathrm{X}_{1} \quad$ : personality

$\mathrm{X}_{2} \quad$ : intention to act

$\mathrm{X}_{3} \quad$ : responsible environmental behavior

\section{HASIL DAN PEMBAHASAN}

Pada hipotesis pertama hasil perhitungan menggunakan uji signifikasi, uji linieritas lalu koefisien jalur untuk penyusunan model persamaan regresi untuk personality $\left(\mathrm{X}_{1}\right)$ terhadap intention to act $\left(\mathrm{X}_{2}\right)$, diperoleh konstanta regresi $\mathrm{a}=52.756$ dan koefisien regresi $\mathrm{b}=0.676$ .Didapatkan hasil analisis jalur (path analysis) dapat dilihat pada tabel berikut :

Tabel 1. Koefisien jalur $\mathrm{X}_{1}$ terhadap $\mathrm{X}_{2}$

\begin{tabular}{|c|c|c|c|c|c|c|c|c|}
\hline \multirow[t]{2}{*}{ Model } & \multicolumn{2}{|c|}{$\begin{array}{l}\text { Unstandardized } \\
\text { Coefficients }\end{array}$} & \multirow{2}{*}{$\begin{array}{l}\text { Standardized } \\
\text { Coefficients } \\
\text { Beta }\end{array}$} & \multirow[t]{2}{*}{$\mathrm{t}$} & \multirow{2}{*}{$\begin{array}{l}\mathrm{t} \\
\text { tabel } \\
(0.05)\end{array}$} & \multicolumn{3}{|c|}{ Correlations } \\
\hline & B & Std. Error & & & & $\begin{array}{l}\text { Zero- } \\
\text { order }\end{array}$ & Partial & Part \\
\hline (Constant) & 52.756 & 9.127 & & 5.780 & & & & \\
\hline Personality & .676 & .100 & .569 & 6.743 & 1.985 & .569 & .569 & .569 \\
\hline
\end{tabular}

a. Dependent Variable: ITA 


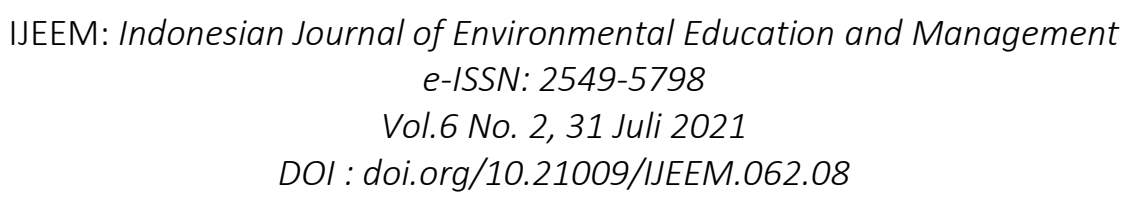

Hasil perhitungan path analysis koefisien jalur $\left(\mathrm{p}_{2.1}\right)$ sebesar 0.569 dengan $\mathrm{t}_{\mathrm{hitung}}=$ $6.743>\mathrm{t}_{\text {tabel }(0,05 ; 95)}=1.985$, yang artinya terdapat pengaruh langsung antara personality terhadap intention to act yang signifikan. Lalu untuk yang hipotesis kedua hasil perhitungan untuk penyusunan model persamaan regresi intention to act $\left(\mathrm{X}_{2}\right)$ terhadap responsible environmental behavior $\left(\mathrm{X}_{3}\right)$, diperoleh konstanta regresi a $=34.790$ dan koefisien regresi $b=0.522$. Dihasilkan uji analisis jalur (path analysis). Hasil perhitungan uji koefisien jalur (path analysis) dapat dilihat pada tabel berikut :

Tabel 2.. Koefisien Jalur ( $X_{2}$ terhadap $\left.X_{3}\right)$

\begin{tabular}{|c|c|c|c|c|c|c|c|c|}
\hline \multirow[t]{3}{*}{ Model } & \multirow{2}{*}{\multicolumn{2}{|c|}{$\begin{array}{l}\text { Unstandardized } \\
\text { Coefficients }\end{array}$}} & \multirow{3}{*}{$\begin{array}{l}\text { Standardized } \\
\text { Coefficients } \\
\text { Beta }\end{array}$} & \multirow[t]{3}{*}{$\mathrm{t}$} & \multirow{3}{*}{$\begin{array}{l}\mathrm{t} \\
\text { tabel } \\
(0.05)\end{array}$} & \multicolumn{3}{|c|}{ Correlations } \\
\hline & & & & & & & & \\
\hline & B & Std. Error & & & & $\begin{array}{l}\text { Zero- } \\
\text { order }\end{array}$ & Partial & Part \\
\hline \multirow{2}{*}{$\begin{array}{ll} & \text { (Constant) } \\
\text { ITA }\end{array}$} & 34.790 & 7.459 & & 4.664 & & & & \\
\hline & .502 & .065 & .621 & 7.714 & 1.985 & .621 & .621 & .621 \\
\hline
\end{tabular}

a. Dependent Variable: REB

Hasil perhitungan path analysis koefisien jalur $\left(\mathrm{p}_{3.2}\right)$ sebesar 0.621 dengan $\mathrm{t}_{\text {hitung }}=$ $7.714>\mathrm{t}_{\mathrm{tabel}(0,05 ; 95)}=1.985$, yang artinya terdapat pengaruh langsung antara intention to act terhadap responsible environmental behavior yang signifikan. Lalu untuk hipotesis ke-tiga hasil perhitungan untuk penyusunan model persamaan regresi personality $\left(\mathrm{X}_{1}\right)$ terhadap responsible environmental behavior $\left(\mathrm{X}_{3}\right)$ diperoleh konstanta regresi $\mathrm{a}=43.310$ dan koefisien regresi $b=0.538$. Tahap setelah uji signifikansi dan linearitas persaman regresi adalah uji analisis jalur (path analysis). Hasil perhitungan uji koefisien jalur (path analysis) dapat dilihat pada tabel berikut : 
Tabel 3. Koefisien Jalur ( $X_{1}$ terhadap $X_{3}$ )

\begin{tabular}{|c|c|c|c|c|c|c|c|}
\hline \multirow[t]{3}{*}{ Model } & \multirow{2}{*}{\multicolumn{2}{|c|}{$\begin{array}{l}\text { Unstandardized } \\
\text { Coefficients }\end{array}$}} & \multirow{3}{*}{$\begin{array}{l}\text { Standardized } \\
\text { Coefficients } \\
\text { Beta }\end{array}$} & \multirow[t]{3}{*}{$\mathrm{t}$} & \multirow{3}{*}{$\begin{array}{l}\mathrm{t} \\
\text { tabel } \\
(0.05)\end{array}$} & \multirow{2}{*}{\multicolumn{2}{|c|}{ Correlations }} \\
\hline & & & & & & & \\
\hline & $\mathrm{B}$ & Std. Error & & & & $\begin{array}{l}\text { Zero- Partial } \\
\text { order }\end{array}$ & Part \\
\hline \multirow{2}{*}{1 (Constant) } & 43.310 & 7.440 & & 5.821 & & & \\
\hline & .538 & .082 & .560 & 6.586 & 1.985 & .560 & .560 \\
\hline
\end{tabular}

a. Dependent Variable: REB

Hasil perhitungan path analysis koefisien jalur $\left(\mathrm{p}_{3.1}\right)$ sebesar 0.560 dengan $t_{\text {hitung }}=$ $6.586>\mathrm{t}_{\text {tabel }(0,05 ; 95)}=1.985$, yang artinya terdapat pengaruh langsung antara personality terhadap responsible environmental behavior yang signifikan. Lalu pada hipotesis ke-empat pengaruh tidak langsung variabel personality terhadap variabel responsible environmental behavior melalui variabel intention to act dapat diperoleh dengan menggunakan rumus sebagai berikut :

$\mathrm{Phi}_{31.2}=\left(\mathrm{Phi}_{21}\right)\left(\mathrm{Phi}_{32}\right)$

Phi $31.2=0.356$

Berdasarkan hasil perhitungan diperoleh $t_{\text {hitung }}=3,656$, hal ini menandakan $t_{\text {hitung }}=$ 3,646 > $\mathrm{t}_{\text {tabel }}=1,896$ Hasil ini menandakan terdapat pengaruh tidak langsung antara personality dan intention to act terhadap responsible environmental behavior. Lalu didapatkan rangkuman hasil sebagai berikut : 
Tabel 4. Rangkuman Hasil Pengujian Hipotesis

\begin{tabular}{llll}
\hline $\begin{array}{l}\text { Hipotesis } \\
\text { Statistitka }\end{array}$ & Koefisien Jalur & $\mathrm{t}_{\text {hitung }}$ & $\begin{array}{l}\mathrm{t}_{\text {tabel }} \\
(0.05)\end{array}$ \\
\hline $\mathrm{H} 0: \rho 21=0$ & 0.569 & 6.743 & 1.985 \\
$\mathrm{H} 1: \rho 21>0$ & & & \\
$\mathrm{H} 0: \rho 32=0$ & 0.621 & 7.714 & 1.985 \\
$\mathrm{H} 1: \rho 32>0$ & & & \\
$\mathrm{H} 0: \rho 31=0$ & 0.560 & 6.856 & 1.985 \\
$\mathrm{H} 1: \rho 31>0$ & & & \\
$\mathrm{H} 0: \rho 31.2=0$ & 0.356 & 3.656 & 1.985 \\
$\mathrm{H} 1: \rho 31.2>0$ & & & \\
\hline
\end{tabular}

Setelah didapatkan hasil pada tabel diatas, maka model empiris sebagai berikut :

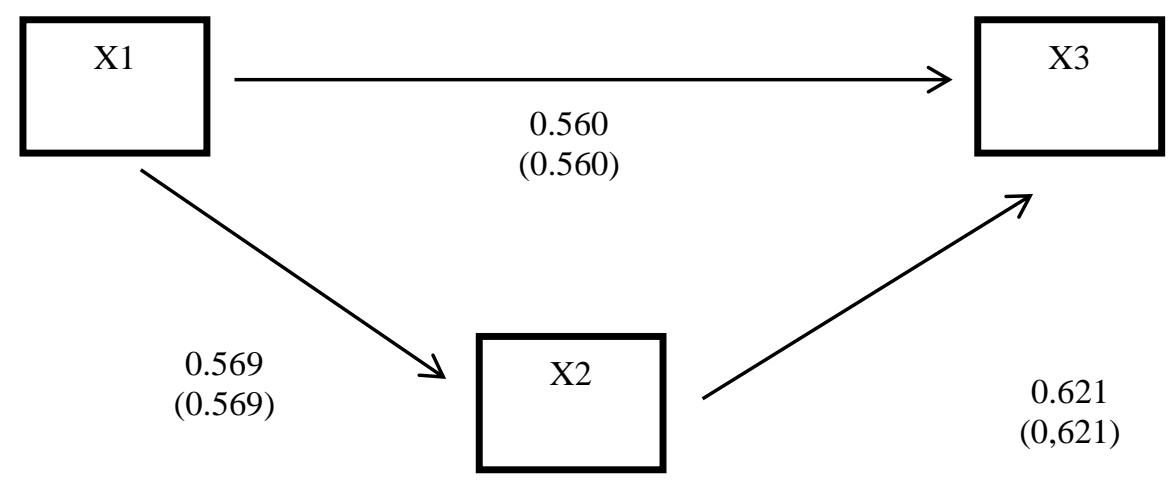

\section{Gambar 3. Model Empirik}

Keterangan :

$\mathrm{X}_{1}$

$\mathrm{X}_{2}$

$\mathrm{X}_{3}$
: Personality

: Intention to Act

: Responsible Environmental Behavior

Berdasarkan hasil pengujian pertama hipotesis antara personality dan intention act mendapatkan hasil yang signifikan. Hal ini membuktikan secara empirik dan teoritik bahwa terdapat pengaruh personality seorang siswa terhadap intention to act yang dimiliki siswa dalam menghadapi permasalahan lingkungan. 


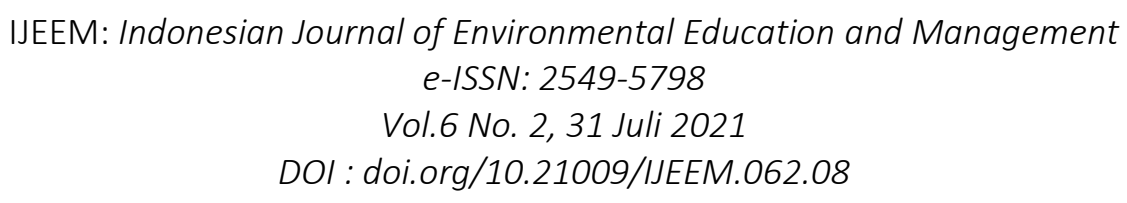

Personality merupakan kepribadian yang dimiliki oleh setiap siswa. Sesuai yang dikemukakan oleh McCrae dan Costa (1997) bahwa kepribadian menggambarkan pola pemikiran , perasaan dan perilaku diberbagai situasi yang membedakan individu satu dengan individu lainnya. Personality memiliki sifat rasa ingin tahu yang dimiliki siswa sehingga dapat memecahkan masalah permasalahan lingkungan. Hasil penelitian Hakim, Putrawan dan Yufiarti (2019) bahwa kepribadian terbentuk juga karena lingkungan sekolahnya. Lingkungan di sekolah akan memunculkan banyak sifat termasuk kedisiplinan. Kedisiplinan dalam mengelola emosi terhadap dirinya dan teman-temannya sejalan dengan munculnya keinginan untuk bertindak (intention to act).

Intention to act merupakan keinginan seseorang dalam melakukan sesuatu tindakan. Keinginan tindakan positif yang dimiliki siswa didukung oleh 5 faktor kepribadian yaitu openness, conscientiouesness, neuroticism, extraversion, dan agreeableness. Hasil penelitian Putrawan (2018) menyatakan bahwa kelima faktor big-five personality mempunyai penaruh terhadap lingkungan terutama extraversion dan openness. Hal ini sesuai dengan model Hines (1987) yang mengungkapkan personality terhubung dengan intention to act seseorang.

Mafabi et.all dalam jurnal Fatria, Putrawan, \& Artanti (2019), menyatakan bahwa keinginan seseorang akan menentukan tindakan yang akan dilakukan. Lalu, didukung oleh Putrawan (2017) bahwa seseorang akan melakukan memiliki sikap yang optimis dengan menunjukkan perilaku yang positif. Perilaku yang positif ini dapat mendukung kesadaran seseorang khususnya siswa dalam menghadapi permasalahan lingkungan.

Hipotesis yang kedua dapat diketahui bahwa intention to act dapat berpengaruh positif terhadap responsible environmental behavior siswa. Hal ini didukung dengan penelitian sebelumnya yaitu Hsu (2010), yang mencoba beberapa variabel literasi yaitu (1) intention to act, locus of control, (3) environmental sensitivity, (4) environmenal attiude, (5) knowledge of environmental issues, (6) knowledge of ecology, (7) Environmental responsibility, (8) knowledge of and skills environmental strategies, dan (9) responsible environmental behavior. Dari kesembilan variabel tersebut, untuk intention to act terdapat pengaruh yang positif terhadap responsible environmental behavior. 


\section{IJEEM: Indonesian Journal of Environmental Education and Management \\ e-ISSN: 2549-5798 \\ Vol.6 No. 2, 31 Juli 2021 \\ DOI : doi.org/10.21009/IJEEM.062.08}

Keinginan untuk bertindak yang dimiliki oleh siswa akan menumbuhkan sikap perilaku tanggung jawab terhadap permasalahan lingkungan. Perilaku tanggung jawab lingkungan akan baik apabila keinginan untuk bertindaknya juga baik. Sesuai dengan model Hines (1987), intention to act memiliki hubungan langsung terhadap responsible environmental behavior. Matakupan, Putrawan \& Neolaka (2019) menyatakan untuk meningkatkan sikap lingkungan siswa dibutuhkan intention to act. Siswa yang berkeinginan tindakan lingkungan yang positif ,akan terbiasa dalam membuang sampah pada tempatnya, mematikan keran air bila tidak dipakai, sehingga akan menumbuhkan perilaku tanggung jawab pada setiap individu siswa.

Berdasarkan hasil pengujian hipotesis ketiga menunjukkan bahwa personality secara langsung dapat mempengaruhi responsible environmental behavior siswa yang signifikan. Hasil penelitian ini sesuai dengan model Hines (1987), di mana faktor-faktor yang dapat mempengaruhi responsible environmental behavior yaitu faktor personality, keinginan akan bertindak, dan faktor situasional. Responsible environmental behavior siswa dapat dipengaruhi oleh personality yang dimiliki siswa. Pengaruh personality ini akan memunculkan perilaku tanggung jawab lingkungan.

Hasil penelitian Daikoban, Putrawan \& Sigit (2019) bahwa siswa dalam memperlakukan lingkunganya berdasarkan karakteristk siswa dalam menghadapi permasalahan lingkungan. Personality mempunyai banyak ciri-ciri sifat sehingga mendukung terjadinya seorang siswa dalam mempertanggung jawabkan perilaku terhadap permasalahan lingkungan. Hal ini didukung oleh Putrawan (2017) menyatakan bahwa seseorang yang suka dan peduli dengan lingkungan beriringan secara otomatis, maka responsible environmental behavior juga positif. Selain itu, Putrawan (2019) menyatakan hasil penelitianya perilaku tanggung jawab lingkungan didukung dengan faktor-faktor yaitu kepribadian, stress, etika, dan hubungan antar sosialnya.

Lingkungan yang dapat terjaga dengan baik, dikarenakan kepribadian yang mempengaruhi perilakunya. Kepribadian menciptakan perilaku sosial seseorang. Siswa misalnya dalam perilaku sosialnya suka mengajak teman dalam mengurangi sampah plastik, atau menegur teman ketika ada yang membuang sampah sembarangan. 


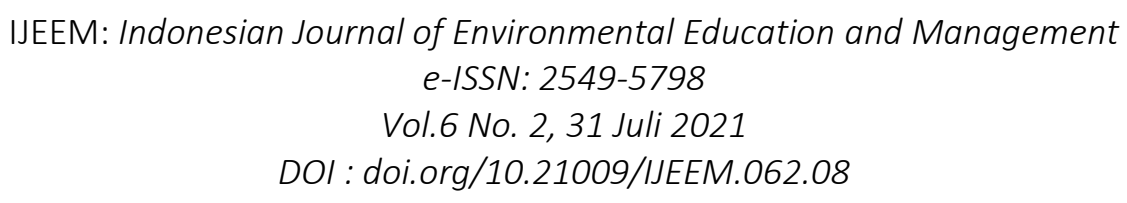

Berdasarkan hipotesis keempat terdapat pengaruh personality terhadap responsible environmental behavior melalui intention to act. Hasil penelitian ini sesuai dengan model Hines (1984), yang dimana personality dan intention to act merupakan faktor yang mempengaruhi siswa memiliki responsible environmental behavior. Responsible environmental behavior akan terbentuk ketika kepribadian yang dimiliki oleh siswa berjalan dengan baik. Setelah kepribadian seorang siswa baik, maka akan berkeinginan untuk melakukan suatu hal yang baik dalam mengelola lingkungan. Personality dan intention to act inilah yang mendukung munculnya responsible environmental behavior siswa. Hal ini menunjukkan bahwa intention to act merupakan variabel mediator yang baik antara personality dengan responsible environmental behavior.

\section{KESIMPULAN}

Beberapa temuan pada penelitian ini, sebagai berikut : (1) Terdapat pengaruh langsung personality terhadap intention to act secara signifikan, (2) Terdapat pengaruh langsung antara intention to act terhadap responsible environmental behavior secara signifikan, (3) Terdapat pengaruh langsung antara personality terhadap responsible environmental behavior secara signifikan, (4) Intention to act baik sebagai mediator variabel antara personality terhadap responsible environmental behavior. Berdasarkan temuantemuan tersebut dapat disimpulkan bahwa variasi personality dan intention to act dapat mempengaruhi responsible environmental behavior siswa. Setiap siswa dapat memiliki responsible environmental behavior sesuai dengan personality dan intention to act yang dimilikinya. Intention to act terdapat pengaruh tidak langsung terhadap responsible environmental behavior, sehingga intention to act baik sebagai mediator variabel antara personality dengan responsible environmental behavior. 


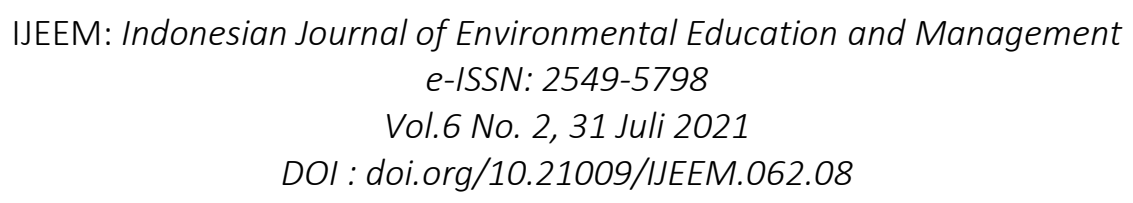

\section{REFERENSI}

Ajzen, Icak. (2011). The Theory of Planned Behavior. Journal of Psychology and Health. 26, (9), 1113-1127.

Akhir, J., Putrawan, I M.,\& Yufiarti. (2019). Environmental Integrity Based on School Climate, Instructional Leadership and Personality.Journal of Adv Research in Dynamical \& Control Systems, 11, 227-232

Blaikie, N. (1993). Education and Environmentalism: Ecological World View And Environmentally Responsible Behaviors. Australian Journal of Environmental Education, 9, 1-20.

Cervone, D. and Pervin, L. A. (2013). Personality: Teory and Research. Twelfth Edition. United States: John Wiley \& Sons, Inc.

Colquitt, J., Jeffery A, L., Michael J, W. (2011). Organizational Behavior. New York:McGraw- Hill.

Daikoban, D., Putrawan, I M.,\& Sigit, D.V. (2019). Students' Personality in Environmental Behavior Based on Students' Attitude, LOC and Personal Responsibility. Test Engineering and Management, 8, 5013-5021.

Dunlap, R. E. and Van Liere, K. D. (1984). Commitment to the dominantsocial paradigm and concern for environmental quality. Oklahoma State University: Social Sci. Q.

Fatria E., Putrawan I. M., Artanti G.D. (2019). Environment and Commitment, Locus of Control and Intention to Act. Indian Journal of Public Health Research \& Development, 7, (9), 1781-1785

Ferraz, S. B., Buhamra, C., Laroche, M., \& Veloso, A. R. (2017). Green Products:A crosscultural study of attitude, intention and purchase behavior. RAM. Revista de Administração Mackenzie, 18, (5), 12 - 38.

Fishbein, M.,\& Ajzen, I.(1975).Belief, attitude, intention and behavior: Anintroduction to theoryand research.

Fishbein, M., \& Ajzen, I. (2011). Predicting and Changing Behavior. New York : Psychology Press.

Gordon, A. (1961). Personality. New York: Holt, Rinehart and Winston. 


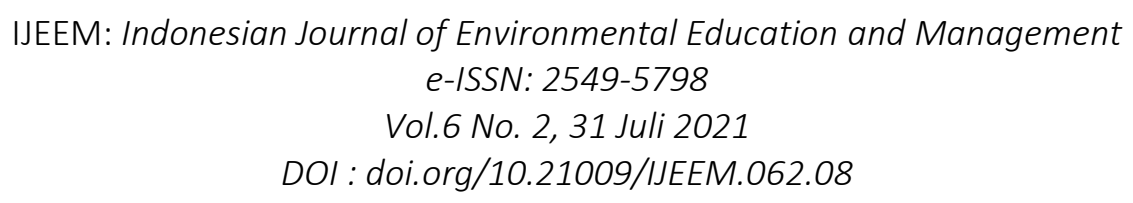

Hakim, A.M, Putrawan, I M.,\& Yufiarti. The Relationship Between Instructional Leadership, Locus of Control and Personality With Citizenship Behavior, International Journal of Innovative Technology and Exploring Engineering, 8, 183-187

Hines, J. M., Hungerford, H. R., Tomera, A. N. (2010). Analysis and Synthesis of Research on Responsible Environmental Behavior: A Meta-Analysis. The Journal of Environmental Education,18, (2), 1-8.

Hsu , Shin Jang. (2010). The Effects of An Environmental Education Program on Responsible Environmental Behavior and Associated Environmental Literal Variables In Taiwanese College Students,35, (2), 37-48.

Hungerford, H. R. dan Volk, T. L. (2013). Changing Learner Behavior Through Environmental Education. The Journal of Environmental Education, 2, (3), 37-41.

Larsen, R. J., \& Buss, D. M. (2002). Personality Psychology: Domains of Knowledge about Human Nature. New York: Mc Graw Hill.

Krajhanzl, J. (2010). Environmental And Proenvironmental Behavior. Health Education: International Experiences, 256.

Laraga, R, (2017). Pengaruh Personality dan Gender terhadap Wawasan Lingkungan. Jurnal Ilmu Administrasi, 6, (1), 43.

Luthans, F. (2006). Perilaku Organisasi. Edisi Sepuluh. Yogyakarta: Penerbit ANDI.

Matakupan, S.J, Putrawan, I.M, Neolaka, A. (2019). The Effect of Personal Commitment and Personal Investment, Intention to Act on Students' Citizenship Behavior. International Journal of Recent Technology and Engineering, 7(6), 803-807

McCrae, R. R., Costa, P. T. Jr. (1997). Personality Trait Structure as a Human Universal. American Psychologist, 52, (5), 509-516.

McCrae, R. R., Costa, P. T. Jr. (2009). The Five-Factor Model of personality traits: consensus and controversy. In P. L. Corr and G. Matthews (eds.). Cambridge: Cambridge University Press.

Marten, G. (2001). Human Ecology, Basic Concept for Sustainable Development. UK: Earthscan

Minsky, M. (1988). The Society of Mind. New York: Simin and Schuster. 


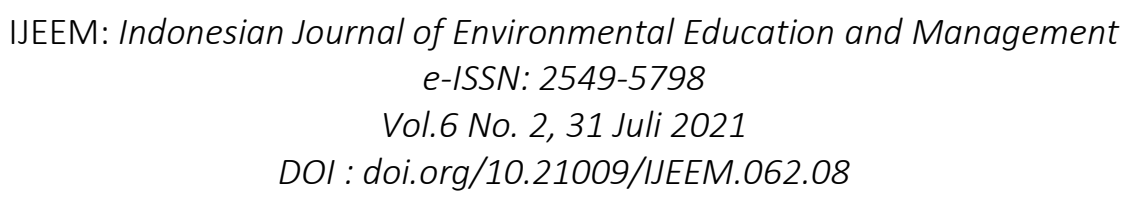

Pan, S. P., Chou, J., Morrison, A. M., Huang W. S., Lin, M. C. (2018). Will the Future Be Greener ? The Environmental Behavioral Intentions of University Tourism Students. Sustainability, 10, (634), 1-5.

Philip C. Short. (2010). Responsible Environmental Action: Its Role and Status In Environmental Education and Environmental Quality. The Jounal of Environment Education, 41, (1), 7-21.

Putrawan, I Made. (2017). Predicting Students' Responsible Environmental Behavior (REB) Based on Personality, Students' New Environmental Paradigm (NEP) and Naturalistic Intelligence. American Scientific Publisher, 23, (9), 8586-8593.

Putrawan, I Made. (2018). Predicting Environmental Leadership Based on Personality and Its Construct Validity. International Journal of Technology and Engineering, 7 , (28), 92-95.

Ramsey, J., Hungerford, H. R., Tomera, A.N. (2010). The effects of environmental action and environmental case study instruction on the overt environmental behavior of eighth-grade students. Journal of Environmental Education, 24-30.

Salim, E. (1986). Pembangunan Berwawasan Lingkungan. Jakarta: LP3ES.

Suryabrata, S. (2008). Psikologi Kepribadian. Jakarta: PT. Raja Grafindo Persada.

Utina, R., dan Wahyuni K.B. (2009). Ekologi dan Lingkungan Hidup. Gorontalo:ISBN.

Widyahastuti, R. dan Anwar, Z. (2013). Effect Of Personality (Big Five Personality) To Multitasking. Advances in Social Science, Education and Humanities Research, 133, 232. 